\title{
KNOWLEDGE, ATTITUDE AND PRACTICE REGARDING FAMILY PLANNING AMONG THE REPRODUCTIVE AGE WOMEN OF KHOPASI, KAVREPALANCHOWK \\ Naresh Manandhar ${ }^{1, *}$, Isha Amatya ${ }^{1}$, Arundhati Gautam², Gaurav Kumar ${ }^{2}$, Himanshu Ahlawat ${ }^{2}$, Nitesh Adhikari², Pawan Kumar Mahaseth ${ }^{2}$ \\ ${ }^{1}$ Department of Community Medicine, Kathmandu Medical College, Sinamangal, Kathmandu, Nepal ${ }^{2}$ MBBS Student, Kathmandu Medical College, Sinamangal, Kathmandu, Nepal.
}

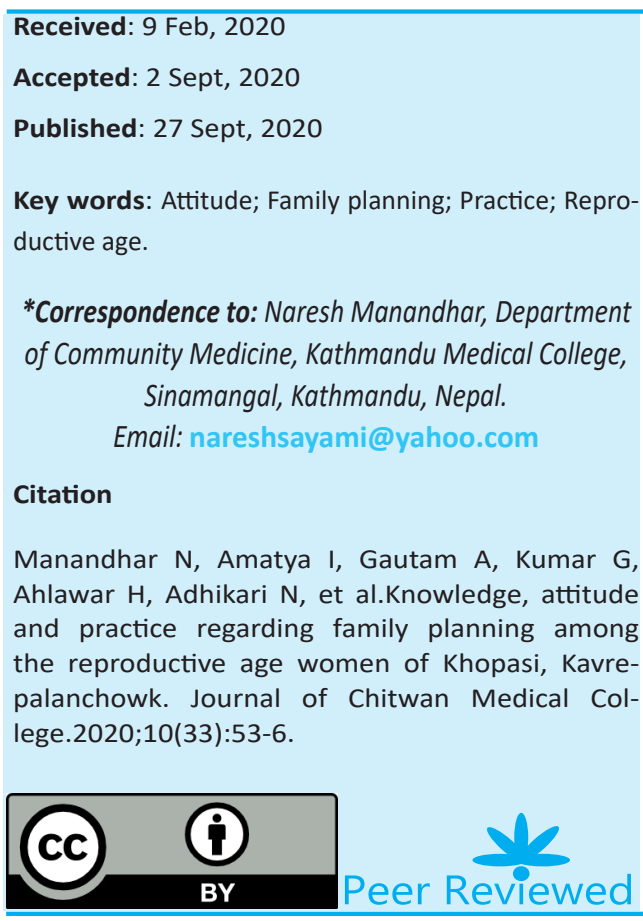

INTRODUCTION

Family planning/child spacing is defined as a conscious effort by a couple to limit or space the number of children they want to have through the use of contraceptive methods. ${ }^{1}$ It is a way of living that is adopted voluntarily on the basis of knowledge, attitude and responsible decision-making by individuals or couples to pin the number, timing and spacing of the children they want, with intention of promoting the health and welfare of the family group, and contribution toward the advancement of the society. ${ }^{2}$ Family planning is a key to slowing unsustainable population growth and the resulting negative impacts on the economy, environment, and national and regional development efforts. 214 million women of reproductive age in developing countries who want to avoid pregnancy are not using a modern contraceptive method. ${ }^{2}$ In Nepal the unmet need for family planning was $24 \%$ in $2016 .{ }^{3}$ Family planning can prevent closely spaced and ill-timed pregnancies and births, which helps to reduce infant mortality rates. ${ }^{4}$

The objective of the study was to assess knowledge, attitude and practice regarding family planning methods among the reproductive age women of Khopasi.

\section{METHODS}

A community based descriptive cross-sectional study was carried out $10^{\text {th }}$ to $15^{\text {th }}$ November, 2019 in Khopasi, Kavrepalanchowk district. Convenience sampling technique was used to select women of reproductive age group. Face to face interviews was conducted by using pre-tested questionnaire. Sample size was calculated by using formula $n=z^{2} p q / e^{2}$, where $p=49 \%$ Contraceptive prevalence rate of Nepal, $q=51 \%, z=1.96$ at $95 \%$ confidence interval and e=8\%. The sample size was 150 reproductive age women.

Ethical approval was taken from the Institutional Review Committee of Kathmandu Medical College. All the respondents were informed about objectives of the study and informed written consent were taken from each respondent.

There were sixteen, thirteen and seven questions to assess the knowledge, attitude and practice of contraceptive respectively. Above the median score were classifies as good and below median score were classifies as poor knowledge, attitude and practice towards family planning. The statistical package for social sciences (SPSS) version 20 was used for data entry and analysis. 
RESULTS

Maximum (25.3\%) respondents were from the age group (2529 ) years followed by $22.7 \%$ from the age group (35-39), $16.7 \%$ from the age group (40-44) and the least $(0.7 \%)$ were from the age group (15-19). The mean age of respondents was 32.2 years with standard deviation of 7.37 years. The mean age of marriage was 18.97 years with standard deviation of 2.7 years and ranged from 13 to 30 years (Table 1 ).

Table 1: Demographic profile of respondents

\begin{tabular}{|c|c|c|}
\hline \multicolumn{2}{|l|}{ Variable } & $\begin{array}{l}\text { No. of Respondent } \\
(\%)\end{array}$ \\
\hline \multirow{7}{*}{ Age Group } & $15-19$ & $1(0.7)$ \\
\hline & $20-24$ & $19(12.7)$ \\
\hline & $25-29$ & $38(25.3)$ \\
\hline & $30-34$ & $22(14.7)$ \\
\hline & $35-39$ & $34(22.7)$ \\
\hline & $40-44$ & $25(16.7)$ \\
\hline & $45-49$ & $11(7.3)$ \\
\hline \multirow{3}{*}{ Religion } & Hindu & $128(85.3)$ \\
\hline & Buddhist & $21(14)$ \\
\hline & Christian & $1(0.7)$ \\
\hline \multirow{4}{*}{ Ethnicity } & Chhetri & $54(36)$ \\
\hline & Brahmin & $29(18.7)$ \\
\hline & Janjati & $2(1.3)$ \\
\hline & Other & $65(43.3)$ \\
\hline \multirow{6}{*}{ Education Status } & No formal education & $63(42)$ \\
\hline & Primary level & $34(22.7)$ \\
\hline & Secondary level & $16(10.7)$ \\
\hline & SLC level & $20(13.3)$ \\
\hline & Higher secondary & $11(7.3)$ \\
\hline & Bachelor's level & $6(4)$ \\
\hline \multirow{4}{*}{ Occupation } & Agricultural & $105(70)$ \\
\hline & Business & $23(15.3)$ \\
\hline & Services & 19(12.7) \\
\hline & Other & $3(2.0)$ \\
\hline
\end{tabular}

Majority (85.3\%) of respondents were Hindu by religion while $14 \%$ of them were Buddhist and $0.7 \%$ were Christianity by religion. The study showed that $36 \%$ were Chhetri and $18.7 \%$ were Brahmin whereas $1.3 \%$ were Janjati and $43.3 \%$ were from another ethnicity.

Most (42\%) of respondents had no formal education. Around $22.7 \%$ of them had completed their primary level of education and only $13.3 \%$ of them had completed SLC level. Similarly, $4 \%$ of had completed their Bachelor's level. Maximum (70\%) of respondents were involved in agricultural occupation followed by business (15.3\%) and services (12.7\%).

All respondents heard about the family planning methods. Regarding knowledge of different family planning methods, more than $90 \%$ of respondents knew about Norplant, Pills, Depo-
Provera and condoms. Similarly, $80.7 \%$ had knowledge about male sterilization and $74.7 \%$ knew about female sterilization while only one fifth had knowledge about emergency contraceptives (Figure 1).

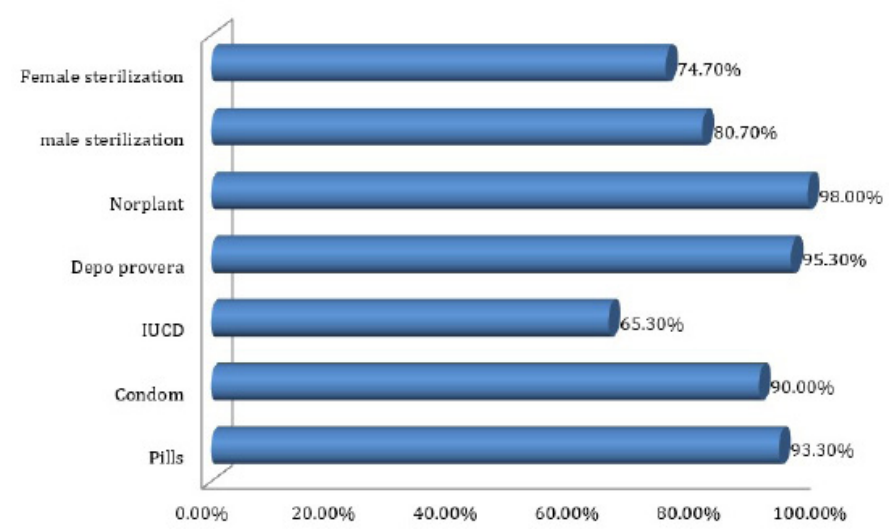

Figure 1: Knowledge regarding different methods of family planning

Women seeking information about the family planning methods were most commonly $(90 \%)$ from the Health Center or Health Assistant. Other sources of information were from Friends (80.7\%), Mass Media (79.3\%), Neighbors (63.3\%), Family Members (60\%) and Relatives (60\%) (Table 2).

Table 2: Sources of information regarding family planning methods (multiple responses)

\begin{tabular}{|l|c|}
\hline Source of information & $\begin{array}{c}\text { No. of Re- } \\
\text { sponses (\%) }\end{array}$ \\
\hline Friends & $121(80.7)$ \\
\hline Neighbors & $9(63.3)$ \\
\hline Health center & $135(90.0)$ \\
\hline Health assistant & $135(90.0)$ \\
\hline $\begin{array}{l}\text { Mass media (Internet, TV, Radio, Newspa- } \\
\text { per) }\end{array}$ & $119(79.3)$ \\
\hline Family members & $90(60.0)$ \\
\hline Relatives & $90(60.0)$ \\
\hline
\end{tabular}

The emergency contraceptive pills should be taken within the 72 hours of conception. Only $20.7 \%$ of women knew about the correct time to take the emergency contraceptive pills while $92.7 \%$ of the women knew about the abortion facilities available in hospital and $77.3 \%$ of the women knew the abortion facilities available in Primary Health Center. Only one fifth had good knowledge about emergency contraceptives (Table 3).

Table 3: Knowledge of emergency contraceptive

\begin{tabular}{|c|c|}
\hline $\begin{array}{c}\text { Knowledge of emergency } \\
\text { contraceptive }\end{array}$ & No. of Responses (\%) \\
\hline Good & $30(20.0)$ \\
\hline Poor & $120(80.0)$ \\
\hline
\end{tabular}

More than half of respondents knew anemia (58\%) and emotional disturbances $(52.7 \%)$ were side effect of abortion followed by pelvic pain (48.7\%). A quarter (24.7\%) of respondents did not 
have knowledge about the side effects of abortion (Figure 2).

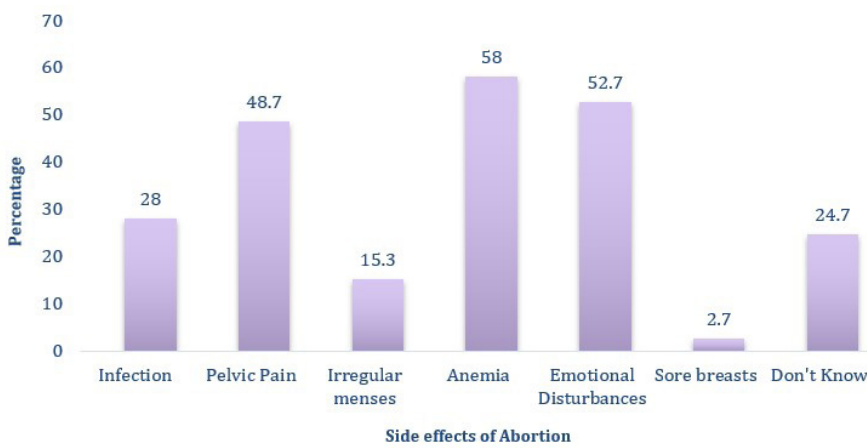

Figure 2: Knowledge on the side effects of abortion

Majority (90\%) of women opined that consent should be taken from husband before aborting whereas $1.3 \%$ of the woman said that consent should be taken from family member and $1.3 \%$ of women don't have knowledge that the consent should be taken before aborting. $7.3 \%$ of women said that the consent should be given themselves. More than half (52\%) of the women had good knowledge regarding family planning.

Regarding the temporary family planning methods, $26.7 \%$ of respondents were using Depo Provera followed by IUCD (2\%) and pills (2\%). Regarding the permanent family planning methods, $12.7 \%$ had undergone female sterilization (Figure 3 ).

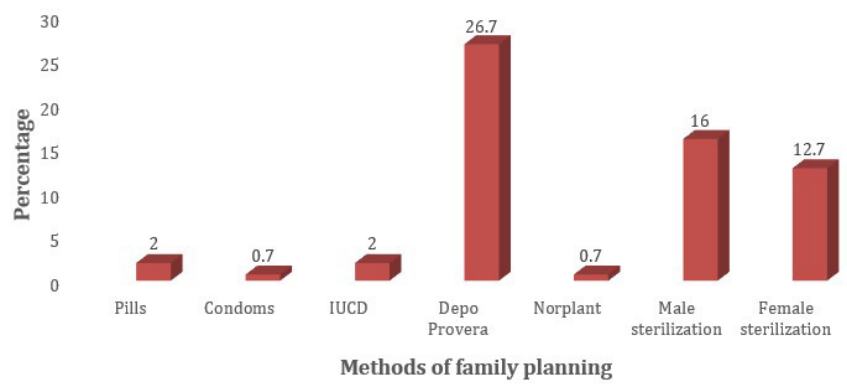

Figure 3: Contraceptives methods users

Majority (98.7\%) of women had positive attitude towards family planning whereas $1.3 \%$ of women had negative attitude towards family planning (Table 4).

Table 4: Attitude towards family planning

\begin{tabular}{|l|c|}
\hline Attitude towards family planning & No. of Responses (\%) \\
\hline Positive & $148(98.7)$ \\
\hline Negative & $2(1.3)$ \\
\hline
\end{tabular}

\section{DISCUSSION}

Knowledge, attitudes toward family planning and practice of contraceptive use are indicators that are used to assess the success of family planning programs. The level of knowledge has an effect on the women to practice family planning more than women who have less knowledge. ${ }^{5}$ Unmet need is anoth- er important indicator of the family planning program and it declined noticeably in Nepal. ${ }^{6}$

Study conducted by Uprety in eastern Nepal revealed that majority $(43.0 \%)$ of the study population belongs to $25-29$ years group; mean age was 27.94 years with SD 6.039 years. Most of them $(83.3 \%)$ were Hindu by religion and $23.7 \%$ of respondents were illiterate. ${ }^{7}$ These findings were consistent with the present study result except mean age of respondents. The mean age of respondents was higher in present study.

In present study, all respondents heard about at least any one method of family planning, which is consistent with the results of NDHS2016, ${ }^{3}$ Lindstrom DP, ${ }^{5}$ Uprety, ${ }^{7}$ Tuladhar $H,{ }^{8}$ and Gupta. ${ }^{9}$ Regarding the knowledge of different family planning methods, more than $90 \%$ of respondents knew about Norplant, Pills, Depo-Provera and condoms. Similarly, $80.7 \%$ had knowledge about male sterilization and $74.7 \%$ knew about female sterilization. This may be due to increasing literacy rate of female and advertisement of family planning methods.

The present study found that $60.8 \%$ respondents were currently using family planning methods which is consistent with finding of NDHS 2016 (53\%), , ${ }^{3}$ Lindstorm (48\%), ${ }^{5}$ Uprety (63.6\%), ${ }^{7}$ Gupta $(68 \%),{ }^{9}$ andDabral $(61.6 \%) .{ }^{10}$ The present study found that $26.7 \%$ of the respondents were using Depo Provera followed by IUCD $(2 \%)$, pills $(2 \%)$, and $12.7 \%$ had undergone female sterilization. These findings were consistent with finding of Nepal demographic health survey where female sterilization (15\%), injectables (9\%), male sterilization (6\%), and the pill (5\%). ${ }^{3} \mathrm{Sev}$ eral studies reported that Injectables hormonal contraceptive was most commonly used family planning method. ${ }^{3,7-9}$ Depo porvera is a good method of contraception for women who desire a long-term, reversible contraceptive method. It assures women of privacy, and is easy to follow up. Most of the respondents chose injectables methods may be due to easily accessible and most of their friends were using.This method was the most common used methods because of the health campaign that offer these facilities conducted in study area.

Only one fifth had knowledge about emergency contraceptives. The knowledge and use of emergency contraception were exceptionally poor. The poor knowledge may be due to lack of education and availability of the emergency contraception in the study area. The women are made to work in house/ field and restricted them to go for education. They were using the family planning methods because of some campaign run in that area.

Present study found that maximum respondents had positive attitude towards family planning and good knowledge regarding family planning which is similar to finding reported in study conducted by Gayathry, India. ${ }^{11}$ Still the unmet need demand of family planning exist. It may be due to not easily accessible, hesitation to visit health center, feeling awkward in openly purchase from medical shop and some socio-cultural barrier with importance of son in family. 
The study was conducted in small sample size in short duration and only one locality. The result of study may not be generalized.

\section{CONCLUSION}

The present study focused on finding out the knowledge, attitude and practice about family planning methods among the reproductive age women. The knowledge about family planning methods was good among the reproductive age women whereas the practice and attitude seemed satisfactory. The knowledge about emergency contraceptive and abortion were poor among the reproductive age women. Continuous effort is needed from the government and local community to educate the public about the safety and convenience of modern, long term and reversible methods of contraception. Promotion of

\section{REFERENCES:}

1. Okonofua F, Lambo E, Okeibunor J, Agholor K. Advocacy for free maternal and child health care in Nigeria - Results and outcomes. Health Policy. 2011; 99(2):131-8. [DOI]

2. Kasa AS, Tarekegn M, Embiale N. Knowledge, attitude and practice towards family planning among reproductive age women in a resource limited settings of Northwest Ethiopia.BMC Res Notes. 2018; 11(1): 577. [DOI]

3. Ministry of Health, Nepal; New ERA; and ICF. 2017. Nepal Demographic and Health Survey 2016. Kathmandu, Nepal: Ministry of Health, Nepal. [LINK]

4. World Health Organization. Family Planning/Contraception. [Last updated on: 2018 Feb 08; Last accessed on 2019 Nov 12]. Available from: [LINK]

5. Lindstrom DP, Hernández CH. Internal Migration and Contraceptive Knowledge and Use in Guatemala, Int Fam Plan Perspect. 2006;32(3):146-53. [DOI] family planning and ensuring access to preferred contraceptive methods for women is essential to securing the well-being and autonomy of women, while supporting the health and development of communities.

\section{ACKNOWLEDGEMENT}

Authors express our deepest gratitude to Professor Dr. Sunil Kumar Joshi, Head of Community Medicine Department at Kathmandu Medical College for his support and guidance. Authors would like to thank all the respondents for their valuable information.

\section{CONFLICT OF INTEREST: None}

\section{FINANCIAL DISCLOSURE: None}

6. Shrestha DR, Shrestha A, Ghimire J. Emerging challenges in family planning programme in Nepal. JNepal Health Res Counc. 2012;10(21):108-12. [DOI]

7. Uprety S, Poudel IS, Ghimire A, Poudel M, Bhattrai S, Baral DD.Knowledge, attitude and practice of family planning among married women of reproductive age in a VDC of eastern Nepal. Journal of Chitwan Medical College.2016, 6(1), 48-53. [DOI]

8. Tuladhar H, Marahatta R. Awareness and practice of family planning methods in women attending gyne OPD at Nepal Medical College Teaching Hospital. Nepal Med Coll J. 2008 ;10(3):184-91. [PMID]

9. Gupta S, Singh A, Gupta N, Shrestha VL.Family Planning Knowledge and Practices among Women in a District Hospital of Nepal. JNMA J Nepal MedAssoc, 2012, 52(188):159-61. [PMID]

10. Dabral S, Malik SL. Demographic study of Gujjars of Delhi: IV. KAP of family planning. J Human Ecol. 2004;16(4):231-7. [DOI]

11. Gayathry D, Moluguri A, Sachin G, Sekhar C. Attitude of couples towards family planning practices in the field practice area of Prathima Institute of Medical Sciences, Karimnagar. Int J Community Med Public Health.2018;5:4816-21. [DOI] 